\title{
Reliability and validity of Healthy Fitness Measurement Scale Version1.0 (HFMS V1.0) in Chinese elderly people
}

Qian Liu ${ }^{1,2 \dagger}$, Hui Zhou ${ }^{3 \dagger}$, Heng Qiu' ${ }^{1}$ Chen Huang ${ }^{1}$, Lijie Jiang ${ }^{4}$, Guli Jiang ${ }^{3}$, Weixuan Wu' ${ }^{1}$ Zhuomin Huang ${ }^{1}$ and Jun $\mathrm{Xu}^{1 *}$

\begin{abstract}
Purpose: We examined the reliability and validity of the Healthy Fitness Measurement Scale Version 1.0 (HFMS V1.0) specifically on elderly people in China.

Methods: We carried out a cross-sectional study in December 2020 and enrolled 800 elderly people through stratified sampling technique, including 777 valid samples (with a mean age of $71.81 \pm 8.36$ years), of which 382 cases (49.2\%) were women. The level of healthy fitness was measured using the HFMS V1.0. The Cronbach's alpha coefficient, split-half reliability, test-retest reliability, convergent and discriminant validity, exploratory factor and confirmatory factor were calculated for assessing the reliability and validity of HFMS V1.0.

Results: HFMS V1.0 consists of 8 dimensions and 38 items. The scale had acceptable reliability (Cronbach's alpha = 0.920 , split-half $=0.946$, test-retest $=0.878$ ). Exploratory factor analysis showed $\mathrm{KMO}$ value $=0.927$, and uncovered 10 factors with the cumulative contribution rate of $65.71 \%$ and all factor loads over 0.40 . The item distribution was consistent with the initial expectation of the scale. The confirmatory factor analysis indicated good fit: CMIN/DF = 2.796, RMSEA $=0.048, I F I=0.914, \mathrm{TLI}=0.902, \mathrm{CFI}=0.913$.

Conclusion: HFMS V1.0 was shown to have acceptable reliability and validity indices for this sample. Collectively, HFMS V1.0 is reliable and efficient to measure the healthy fitness of elderly people. It is recommended to use it among the elderly in other Chinese cities in the future to ensure uniformity and objectivity. This scale can be carried out to evaluate of the effectiveness of public health measures in improving the healthy fitness level of the elderly and optimizing public health policies.
\end{abstract}

Keywords: Healthy fitness measurement scale version 1.0 (HFMS V1.0), Chinese elder people, Reliability, Validity

\section{Introduction}

The increase in life expectancy and the decline in fertility are facilitating the aging of the world's population [1]. By the end of 2019, China's elderly population has exceeded 250 million, accounting for $18.1 \%$ of the total

\footnotetext{
* Correspondence: drugstat@163.com

${ }^{\dagger}$ Qian Liu and Hui Zhou contributed equally to this work.

'Department of Sanitation Economy Administration, Nanfang Hospital, Southern Medical University, Guangzhou, Guangdong Province, China Full list of author information is available at the end of the article
}

population [2]. By 2053, China's elderly population will reach the peak of population aging. From 2000 to 2050, the ratio of China's population aging will increase from 10 to $34 \%$, over two times as the global growth rate [3]. The disease spectrum in China has begun to transit from infectious diseases to non-communicable diseases. The prevalence of chronic non-communicable diseases will increase by at least $40 \%$ by 2030 , when approximately $80 \%$ of people aged 60 and over will die from chronic non-communicable diseases. Whether an aging

(c) The Author(s). 2021 Open Access This article is licensed under a Creative Commons Attribution 4.0 International License, which permits use, sharing, adaptation, distribution and reproduction in any medium or format, as long as you give appropriate credit to the original author(s) and the source, provide a link to the Creative Commons licence, and indicate if changes were made. The images or other third party material in this article are included in the article's Creative Commons licence, unless indicated otherwise in a credit line to the material. If material is not included in the article's Creative Commons licence and your intended use is not permitted by statutory regulation or exceeds the permitted use, you will need to obtain permission directly from the copyright holder. To view a copy of this licence, visit http://creativecommons.org/licenses/by/4.0/ The Creative Commons Public Domain Dedication waiver (http://creativecommons.org/publicdomain/zero/1.0/) applies to the data made available in this article, unless otherwise stated in a credit line to the data. 
population can create a "third demographic dividend" for society depends heavily on the health [4]. Biological aging is characterized by physical weight loss [5], decline in organ function [6], and psychological memory [7], emotional instability, and reduced adaptability [8]. Due to reduced adaptability in many aspects, the prevalence of chronic diseases in the elderly is $2.3-3.2$ times that of the total population [9]. Therefore, it is imperative to strengthen the healthy fitness management of the elderly. The concept of "health" "Health is not only the absence of disease and infirmity, but also a state of physical, mental and social well-being") was introduced by WHO in 1947 [10]. Fitness refers to the individual's ability to actively or passively adapt to changing environment, including all physical, mental and social responses [11]. Sturmberg proposed that the dynamic adaptive relationship between the individual and internal and external factors determines the state of health [12]. There is an increasing body of evidence supporting that fitness levels relate to current and future individuals' health status [13]. A high level of fitness allows people to effectively cope with the internal and external events and to restore to a balanced state following stress reaction and adjustments; otherwise, individual with poor fitness are more vulnerable to health impacts of external forces and even many diseases [14]. Fitness is an indispensable ability for people living in modern society, also an important factor in health [15].

Physical fitness is the ability to cope with daily work without undue fatigue, and with energy to enjoy leisure and respond to emergencies [16]. Physical fitness is closely related to health-related quality of life [17]. Studies have shown that good Physical fitness can have a protective effect against certain cancers and reduce the risk of cardiovascular disease and metabolic syndrome [18]. Physical exercise is an important way to enhance healthy physical fitness [19]. By measuring the physical fitness status of individuals, it can effectively guide them to participate in physical exercise and develop healthy awareness and behavior. It is now common practice in some countries to develop and implement various physical fitness testing and evaluation standards. The physical fitness test in the United States was traced back to the 1880s [20]. The Physical Best (PB) is currently prevalent test for assessing physical fitness [21], whose selected indicators consist of cardiopulmonary function, muscle strength and endurance, flexibility and body composition. The Japanese physical fitness tests are made up of different test items based on age and grade, with grip strength, sit-ups and sit-and-reach as general items [22, 23]. China's physical fitness test was developed late, and the test follows National Fitness Standards covering all people different ages (from infants, children and adolescents, adults to the elderly) [24].
However, the above-mentioned tests rely on professional assessors and are limited by the availability of space and equipment. At the same time, subjects with sudden illnesses such as colds, sports injuries, and cardiovascular diseases as "exemptions" in the testing process [25], so that individuals with weak economic and health conditions cannot know their own physical fitness level. Therefore, it is necessary to develop a convenient, effective, and reliable fitness self-assessment tool to allow individuals to understand their own physical fitness status in real time and to guide them to effectively carry out physical fitness promotion activities.

Martin Prince emphasizes the separate contributions of mental and physical illness to disability and mortality, and suggests that there is no health without mental health [26]. The epidemic of psychosocial distress and mental ill health have become major threats to people's well-being [27]. Therefore, mental fintess is also an important aspect of healthy fitness assessment. Mental fitness is defined as the interaction between an individual and a changing environment, and it is a dynamic process of individual psychological self-regulation [28]. Mental fitness is closely related to disease progression and people's physical health [29]. Paula Robinson [30] describes mental fitness as the capacity to use one's resources and skills to flexibly adapt to environmental changes, and proposes that mental fitness can be measured, when the mental fitness can be understood in a similar way to physical fitness. Linda Bolier [31] pointed out that positive thinking and problem-solving capacity has a positive effect on health. Different from the quantitative assessment of physical fitness using instruments and equipment, evaluation of mental fitness at home and abroad is mostly carried out by the scale or the evaluation index system, such as Adolescence Psychological Adaptability Scale (APAS) [32] for evaluating the psychological adaptability of adolescents, Symptom Check List-90 (SCL-90) [33] for evaluating mental health status, and Self-Rating Anxiety Scale (SAS) for evaluating psychological anxiety [34].

Social fitness is defined as the ability of individuals to adjust their own body and psychological state to achieve the goals expected by the society [35], particularly encompassing the availability and compatibility of social environment [36]. This kind of fitness is affected by both internal and external factors [37]. Individuals with lower level of social adaptability are more prone to maladaptation with symptoms such as fear and cringe, and even environmental shock [38-40]. At present, there have been some researches on the measurement of individual social adaptiveness and adaptability at home and abroad, such as Vineland Social Maturity Scale (VABS) [41] and the Social Adaptation Self-evaluation Scale (SASS) [42], American Association for Mental Deficiency Adaptive 
Behavior Scales (AAMD ABS) [43], and Psychosomatic Symptom Scale (PSSS) [44].

Fore-mentioned studies on adaptability evaluation mostly focus on a certain aspect of fitness other than integration of physical, mental and social fitness. In 1948, World Health Organization (WHO) defined health as a state of the absence of illness or weakness, and the presence of physical, psychological, and social well-being [45], discarding the narrow concept of "health", but encompassing psychological and social well-being. Social competence and adaptability have become essential to health. Therefore, comprehensive assessment of adaptability should not only include measures of physical fitness (health-related physical fitness), but also detect mental and social fitness [46]. On the basis of previous studies on physical fitness and health-related physical fitness, our previous study put forward with the concept of "healthy fitness" [47]: the best physical, mental and social adaptability. Further, Jun Xu et al. established a healthy fitness assessment index system of Healthy Fitness Measurement Scale Version 1.0 (HFMS V1.0) involving physical, mental and social fitness when considering China's social culture [48] .Herein, our study aimed to determine the reliability and validity of HFMS V1.0 applied to the elderly, and provide a convenient and efficient self-reporting tool for health fitness evaluation, allowing medical institutions and public health practitioners to conduct targeted behavioral interventions and health guidance for the elderly to prevent harmful effects secondary to decreased health fitness.

\section{Materials \& methods}

\section{Study design}

This a cross-sectional and multistage survey was conducted using a random sampling technique in December 2020. The first stage involved 4 administrative districts within Guangzhou while considering their economic level and geographical distributions. The second stage involved $1 \sim 3$ streets of the selected districts. The final stage involved sampling of $1 \sim 2$ neighborhood committees from the selected streets. Finally, elderly people in eight elderly care institutions and community hospitals in four administrative districts (Huangpu, Yuexiu, Liwan, Baiyun) of Guangzhou city were included in this study. These facilities were selected mainly due to their location close to our institution. For subjects who met our inclusion criteria and agreed to participate in our study, the random sampling was conducted based on gender (male: female $=1: 1)$ and age $((60-64):(65-69):(70-74)$ : $(75-79):(80$ years and older $)=1: 1: 1: 1: 1: 1)$.

\section{Participants}

The sample size was at least 10-15 individuals per item for the factor analysis. If the sample size was more than
20 individuals per item for the factor analysis, the results of factor analysis would be more stable and reliable [49]. The sample size was calculated as 680 with 20 individuals each item. Considering shedding, the final sample size was set to 800 . All participants completed the test and 80 of them participated in the retest over an interval of $24 \mathrm{~h}$ to 1 week. Inclusion criteria included the following: age over 60 years old, local residents or non-local residents who have lived for more than half a year, and willingness to participate in this survey. Exclusion criteria were cognitive decline and a history of illness within this month. In the first test, 777 valid questionnaires (male, 50.8\%) were returned, with effective response rate of $97.13 \%$. Seventy-four valid questionnaires were retested and returned, with effective recovery rate of $92.50 \%$. Informed written consent was obtained from all subjects.

\section{Healthy fitness assessment}

A number of sociodemographic variables were set in this study, including: gender, age, educational background, marital status, household monthly income, personal monthly income, pre-retirement occupation, participation in insurance. The age range was classified into five groups: "60 to 64 years old", "65 to 69 years old", "70 to 74 years old", "75 to 79 years old", and "over 80 years old". The educational background of the respondents was categorized as: "uneducated", "primary school diploma", "junior high school diploma", "high school/technical secondary school/vocational high school diploma", "college degree", "bachelor degree and above". The marital status was classified into five groups: "single", "married", "divorced", "widowed", "others". The household monthly income of the respondents was categorized as: "RMB 3000-RMB 6000", "RMB 6001-RMB 9000", "RMB 9001-RMB 12000", "Over RMB 12001". The personal monthly income of the respondents was categorized as: "Less than RMB 2000", "RMB 2001-RMB 4000", "RMB 4001-RMB 6000", "RMB 6001-RMB 8000”, "Over RMB 8001". The pre-retirement occupation was indicated as: "Heads of state agencies, party organizations, enterprises, and institutions", "Professional technicians (teachers, doctors, etc.)", "Clerks and related personnel", "Commercial and service personnel", "Production personnel in agriculture, forestry, animal husbandry, fishery and water conservancy", "Production, transport and equipment operators and related occupations", "Soldier", "Other practitioners". The participation in insurance was denoted as: "Self-pay", "Public medical insurance", "Medical insurance for urban and rural residents", "Urban employee medical insurance", "Commercial medical insurance".

Healthy fitness was the adaptability outcome analyzed in this study. This was measured using the Health Measurement Scale version 1.0 (HFMS V1.0), which had been 
Table 1 Participant's demographic characteristics $(n=777)$

\begin{tabular}{l} 
Characteristi \\
\hline Gender \\
Male \\
Female \\
Age (years old) \\
$60-64$ \\
$65-69$ \\
$70-74$ \\
$75-79$ \\
$80-$
\end{tabular}
Number Percent

Education

Uneducated
Primary school diploma
Junior high school diploma
High school/technical secondary school//
vocational high school diploma
College degree
Bachelor degree and above
Marital status
Single
Married
Divorced
Widowed
Others

Household monthly income per person (yuan)

$$
<3000
$$

3000-6000

6001-9000

$9001-12,000$

$>12,000$

Personal monthly income (yuan)

$$
<2000
$$

2000-4000

4001-6000

$6001-8000$

$>8000$

Pre-retirement occupation

Heads of state agencies, party organizations, enterprises, and institutions

\section{Professional technicians (teachers, doctors, etc.)}

Clerks and related personnel

Commercial and service personnel

Production personnel in agriculture, forestry, animal husbandry, fishery and water conservancy

Production, transport and equipment operators and related occupations
Table 1 Participant's demographic characteristics $(n=777)$ (Continued)

\begin{tabular}{lll}
\hline Characteristic & Number & Percent \\
\hline Soldier & 4 & 0.5 \\
Other practitioners & 98 & 12.6 \\
Participation in insurance & & \\
Self pay & 25 & 3.2 \\
Public medical insurance & 402 & 51.7 \\
Medical insurance for urban and rural residents & 189 & 24.3 \\
Urban employee medical insurance & 235 & 30.2 \\
Commercial medical insurance & 50 & 6.4 \\
\hline
\end{tabular}

previously developed by our research group. This scale conforms to operational definition of healthy fitness and has been analyzed and confirmed by the expert and field investigation [48]. HFMS V1.0 consists of three subscales: physical fitness status (PF), mental fitness status (MF), and social fitness status (SF). PF consists of 14 items that comprises three factors: organic function, motor function and physical adaptive capacity. MF consists of 11 items that comprises three factors: psychological cognition, resilience and stress response. SF consists of 9 items that comprises two factors: role adaptation and social resource and social support. Forward scoring must be adopted for the 1-5, 16-17, 28-36 with the score equal to the original score, while reverse scoring (6-1) must be adopted for the items $6-14,18-26$, and items $15,27,37$, and 38 were the overall evaluation items and not calculated. The scale used Likert 5-point method ( $1=$ very poor, $2=$ poor, $3=$ moderate, $4=$ good, $5=$ very good). The original score of each dimension was computed as the sum of the scores of each subordinate items, and the original score of each subscale was computed as the sum of the scores of each subordinate dimensions. The gross score of the scale was computed by the sum of the scores of the three subscales. For better analysis, comparison, and popularization, the raw scores of each dimension and each scale are converted to percentile value with formula as follows. The higher the conversion score, the higher the fitness level [48].

$$
\text { Conversion score }=\frac{\text { Original score-Theoretical Maximum }}{\text { Theoretical Maximum-Theoretical Maximum }} * 100
$$

\section{Quality control}

The uniformly trained investigators sent out the questionnaire to the subjects, and introduced the filling method and precautions. The subjects were required to respond independently and completed the questionnaire by themselves based on their own healthy fitness in the past month. If the participants have trouble in reading the questionnaires, the investigator may provide 
appropriate assistance to them without any inducing prompts. In order to ensure the quality of the questionnaires, all questionnaires were collected on the spot, and those with more than 6 missing items, inconsistent answers, regular answers, or highly repeated answers were excluded.

\section{Statistical analysis}

Missing values are filled using multiple interpola$\operatorname{tion}(m=5)$ [50]. All data were processed by IBM SPSS 25.0 software and AMOS 21.0 software. Quantitative data were described as $\left({ }^{-} \mathrm{X} \pm \mathrm{S}\right)$ and count data were described as percentage. Reliability denotes the ability of a

Table 2 The descriptions of each item of the HFMS V1.0 $(N=777)$

\begin{tabular}{|c|c|c|c|c|c|c|}
\hline Subscale & Dimension & Item & Mean & SD & Skewness & Kurtosis \\
\hline \multirow[t]{14}{*}{ Physical Fitness Subscale } & \multirow[t]{5}{*}{ Organic Function } & 1. Shapely & 3.02 & 0.82 & -0.26 & 0.08 \\
\hline & & 2. vision & 2.93 & 0.78 & -0.13 & -0.20 \\
\hline & & 3. hearing & 3.14 & 0.82 & -0.42 & -0.17 \\
\hline & & 4. Head discomfort & 3.45 & 0.85 & -0.31 & 0.23 \\
\hline & & 5. Palpitation & 3.62 & 0.87 & -0.18 & -0.10 \\
\hline & \multirow[t]{5}{*}{ Motor Function } & 6. Climb 3-5 floors & 2.92 & 0.90 & 0.17 & 0.04 \\
\hline & & 7. $1000 \mathrm{~m}$ walk & 3.23 & 1.10 & 0.03 & -0.81 \\
\hline & & 8. Bend over to touch toes & 2.79 & 1.04 & 0.17 & -0.52 \\
\hline & & 9. Daily housework & 3.30 & 0.88 & -0.03 & -0.05 \\
\hline & & 10. Participate in strenuous activities & 2.63 & 0.91 & 0.25 & -0.13 \\
\hline & \multirow[t]{4}{*}{ Physical Adaptive Capacity } & 11. Easy to catch colds and allergies & 3.18 & 0.78 & 0.08 & -0.13 \\
\hline & & 12. Noise, light interference & 2.99 & 0.86 & 0.16 & -0.17 \\
\hline & & 13. Cold resilience & 3.26 & 0.79 & -0.17 & -0.20 \\
\hline & & 14. Relieve discomfort & 3.43 & 0.87 & -0.23 & -0.48 \\
\hline \multirow[t]{11}{*}{ Mental Fitness Subscale } & \multirow[t]{2}{*}{ Psychological Cognition } & 16. Focus & 3.25 & 0.78 & -0.15 & -0.46 \\
\hline & & 17. memory & 2.81 & 0.78 & 0.16 & -0.48 \\
\hline & \multirow[t]{4}{*}{ Resilience } & 18. Strive to achieve the goal & 3.25 & 0.78 & 0.00 & 0.14 \\
\hline & & 19. Drop goal & 3.24 & 0.79 & 0.18 & 0.45 \\
\hline & & 20. There is hope in the future & 3.39 & 0.82 & 0.12 & -0.29 \\
\hline & & 21. Discouraged by failure & 3.44 & 0.77 & 0.21 & 0.05 \\
\hline & \multirow[t]{5}{*}{ Stress Response } & 22. loneliness & 3.71 & 0.90 & -0.10 & -0.66 \\
\hline & & 23. feeling scared & 3.87 & 0.85 & -0.28 & -0.53 \\
\hline & & 24. upset & 3.56 & 0.75 & 0.15 & -0.39 \\
\hline & & 25. Restless & 3.75 & 0.81 & -0.07 & -0.60 \\
\hline & & 26. nervous & 3.60 & 0.75 & 0.07 & -0.38 \\
\hline \multirow[t]{9}{*}{ Social Fitness Subscale } & \multirow[t]{4}{*}{ Role Adaptation } & 28. Family relations & 3.55 & 0.82 & -0.56 & 0.49 \\
\hline & & 29. Unpleasant handling & 3.55 & 0.80 & -0.39 & 0.11 \\
\hline & & 30. Adapt to role changes & 3.49 & 0.91 & -0.31 & -0.40 \\
\hline & & 31. Self-role evaluation & 3.55 & 0.80 & -0.46 & 0.25 \\
\hline & \multirow[t]{5}{*}{ Social Resource and Social Support } & 32. Connect with relatives and friends & 3.41 & 0.81 & -0.02 & -0.37 \\
\hline & & 33. Support from relatives and friends & 3.29 & 0.82 & -0.23 & 0.01 \\
\hline & & 34. Proactively seek help & 2.92 & 0.80 & 0.08 & 0.06 \\
\hline & & 35. Share with others & 3.18 & 0.84 & 0.18 & -0.21 \\
\hline & & 36. Close friends & 3.33 & 0.85 & 0.11 & -0.13 \\
\hline \multirow[t]{4}{*}{ Overall evaluation item } & & 15. Overall evaluation of physical fitness & 3.23 & 0.68 & -0.07 & 0.00 \\
\hline & & 27. Overall evaluation of mental fitness & 3.28 & 0.72 & -0.10 & 0.08 \\
\hline & & 37. Overall evaluation of social fitness & 3.45 & 0.71 & -0.15 & 0.08 \\
\hline & & 38. Overall assessment of healthy fitness & 3.42 & 0.70 & -0.17 & 0.34 \\
\hline
\end{tabular}


scale to produce consistent results when completed under similar conditions, whereas validity denotes the extent to which a scale measures the construct it is supposed to. Reliability of the questionnaire as internal consistency was determined using split-half method and Cronbach's alpha coefficient. Cronbach's alpha coefficient of 0.81 to 1.00 indicates almost perfect agreement, 0.61 to 0.80 indicates agreement, 0.41 to 0.60 indicates moderate agreement [51]. Split-half method reliability was assessed by calculating the 34 odd- and evennumbered items after removing 4 overall items not involved in scoring, with its coefficient over 0.70 considered satisfactory [52]. The intraclass correlation coefficient (ICC) was calculated for evaluating test-retest reliability with values less than 0.5 , between 0.5 and 0.75 , between 0.75 and 0.9 , and greater than 0.90 indicative of poor, moderate, good, and excellent reliability, respectively [53]. Validity was evaluated using convergent and discriminant validity, as well as factor analysis consisting of exploratory factor analysis (EFA) and confirmatory factor analysis (CFA). Examination of convergent and discriminant validity included evaluation of spearman's correlation coefficient [54]. In general, great convergent and discriminant validity is characterized by the correlation coefficient between each dimension value and the total value higher than that between each dimension; the correlation coefficient between each dimension and the scale's total score $>0.40$ [55]. For EFA, we used the Kaiser-Meyer-Olkin (KMO) test and Bartlett's test of sphericity to measure the adequacy of samples when determining whether KMO value is between 0.5 and 1 [56]. Principal components analysis (PCA) was used to obtain common factors. In order to determine the factor structure, the orthogonal rotation axis was performed by the varimax rotation. CFA was performed to assess the measurement model. Good model fit [57] included chi-square $(\mathrm{CMIN} / \mathrm{DF})<3.00$, root mean square error of approximation (RMSEA) < 0.05 , incremental fit index (IFI) $>0.900$, Tucker-Lewis index $(\mathrm{TLI})>0.900$, comparative fit index $(\mathrm{CFI})>0.900$. $* p<0.05$ indicates significant difference.

\section{Results}

\section{Description of sample}

The demographics of all participants are shown in Table 1. Of the 777 participants, males accounted for a larger proportion $(50.8 \%)$ with most in the 65-69 age group (26.1\%). Education of the most participants was junior high school and above (76.2\%), and most of the participants were married (79.9\%). Their pre-retirement occupations were mainly heads of state agencies, party organizations, enterprises, and institutions (34.2\%), and a majority participated in public medical insurance (57.1\%).

\section{Validity \\ Exploratory factor analysis}

Table 2 showed the descriptions of each item. Since Skewness and Kurtosis values are all less than 2, all of the items were retained in the exploratory factor analysis.

A KMO test was used in research to determine whether the sampling adequacy of data are to be used for factor analysis. As a consequence, the data of high KMO value (0.927) demonstrated that a factor analysis may be useful; meanwhile the approximate chi-square distribution of Bartlett test was 10,646.015, the degree of freedom was 561, $(p<0.001)$, refuting the hypothesis

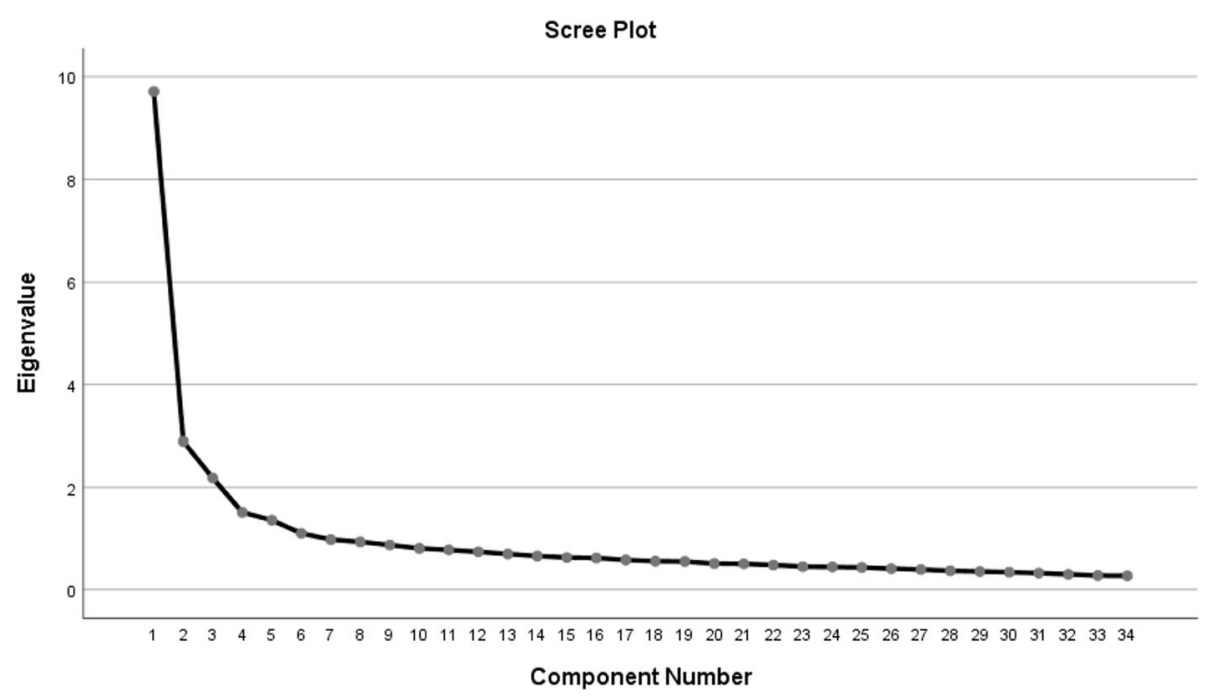

Fig. 1 The Scree plot of HFMS V1.0 
that the correlation matrix is not an identity matrix. This indicates that 34 items have common factors and therefore are suitable for factor analysis [58]. In the PCA, Combined scree plot (Fig. 1), factor loading matrix and previous theoretical inferences, 10 factors were extracted and the cumulative contribution rate reached $65.71 \%$. Table 3 showed the item distribution of the 10 factors was roughly in line with the theory of scale compilation with the factor loads higher than 0.4 after the orthogonal rotation axis is performed by the varimax rotation (factor 1: Motor function; factor 2: Role adaptation; factor 3: Stress response; factor 4: Resilience; factor 5 and factor 7: Organ function; factor 6 and factor8: Social resource and social support; factor 9: Physical adaptive capacity; factor10: Psychological cognition).

Table 3 Factor loading matrix and contribution rate of each factor

\begin{tabular}{|c|c|c|c|c|c|c|c|c|c|c|}
\hline & Factor1 & Factor2 & Factor3 & Factor4 & Factor5 & Factor6 & Factor7 & Factor8 & Factor9 & Factor 10 \\
\hline HF1 & 0.408 & & & & 0.447 & & & & & \\
\hline HF2 & & & & & 0.797 & & & & & \\
\hline HF3 & & & & & 0.698 & & & & & \\
\hline HF4 & & & & & & & 0.709 & & & \\
\hline HF5 & & & & & & & 0.607 & & & \\
\hline HF6 & 0.750 & & & & & & & & & \\
\hline HF7 & 0.751 & & & & & & & & & \\
\hline HF8 & 0.664 & & & & & & & & & \\
\hline HF9 & 0.654 & & & & & & & & & \\
\hline HF10 & 0.810 & & & & & & & & & \\
\hline HF11 & 0.439 & & & & & & & & 0.523 & \\
\hline HF12 & & & & & & & & & 0.581 & \\
\hline HF13 & & & & & & & & & 0.504 & \\
\hline HF14 & & & & & & & & & 0.422 & \\
\hline HF16 & & & & & & & & & & 0.701 \\
\hline HF17 & & & & & & & & & & 0.655 \\
\hline HF18 & & & & 0.686 & & & & & & \\
\hline HF19 & & & & 0.762 & & & & & & \\
\hline HF2O & & & & 0.671 & & & & & & \\
\hline HF21 & & & 0.428 & 0.622 & & & & & & \\
\hline HF22 & & & 0.492 & 0.424 & & & & & & \\
\hline HF23 & & & 0.732 & & & & & & & \\
\hline HF24 & & & 0.782 & & & & & & & \\
\hline HF25 & & & 0.754 & & & & & & & \\
\hline HF26 & & & 0.715 & & & & & & & \\
\hline HF28 & & 0.529 & & & & & & & & \\
\hline HF29 & & 0.706 & & & & & & & & \\
\hline HF30 & & 0.788 & & & & & & & & \\
\hline HF31 & & 0.757 & & & & & & & & \\
\hline HF32 & & 0.500 & & & & & & & & \\
\hline HF33 & & 0.442 & & & & & & 0.652 & & \\
\hline HF34 & & & & & & & & 0.838 & & \\
\hline HF35 & & & & & & 0.825 & & & & \\
\hline HF36 & & & & & & 0.690 & & & & \\
\hline Contribution rate (\%) & 28.558 & 8.508 & 6.416 & 4.441 & 3.993 & 3.235 & 2.878 & 2.743 & 2.564 & 2.374 \\
\hline Cronbach's alpha coefficient & 0.843 & 0.804 & 0.839 & 0.790 & 0.623 & 0.764 & 0.573 & 0.532 & 0.719 & 0.550 \\
\hline
\end{tabular}




\section{Confirmatory factor analysis}

Combined with the secondary structure of the HFMS V1.0 scale, a second order CFA structure was modeled, as shown in Fig. 2. The correlation coefficients among the three subscales of PF, MF, and SF were 0.59, 0.86, 0.75 , and the standardized path coefficients between the dimensions and the subscales ranged from 0.78 to 0.95 . The path coefficients of most items over 0.50 indicated that HFMS V1.0 has a large effect with great path association. The initial model was not well fitted $(\mathrm{CMIN} / \mathrm{DF}=$
3.647, RMSEA $=0.058$, IFI $=0.867, \mathrm{TLI}=0.855, \mathrm{CFI}=$ 0.867.), so covariation relationship between the error variables was established in turn by combining the Modification Indices and Estimated parameter change for covariance. After the correction, the model showed good fit: $\mathrm{CMIN} / \mathrm{DF}=2.796$, RMSEA $=0.048$, IFI $=0.914$, $\mathrm{TLI}=0.902$, CFI $=0.913$.

The calculated correlation coefficients between dimensions and subscales score had a range of $0.597-0.886$, showing that the dimensions and subscales scores had

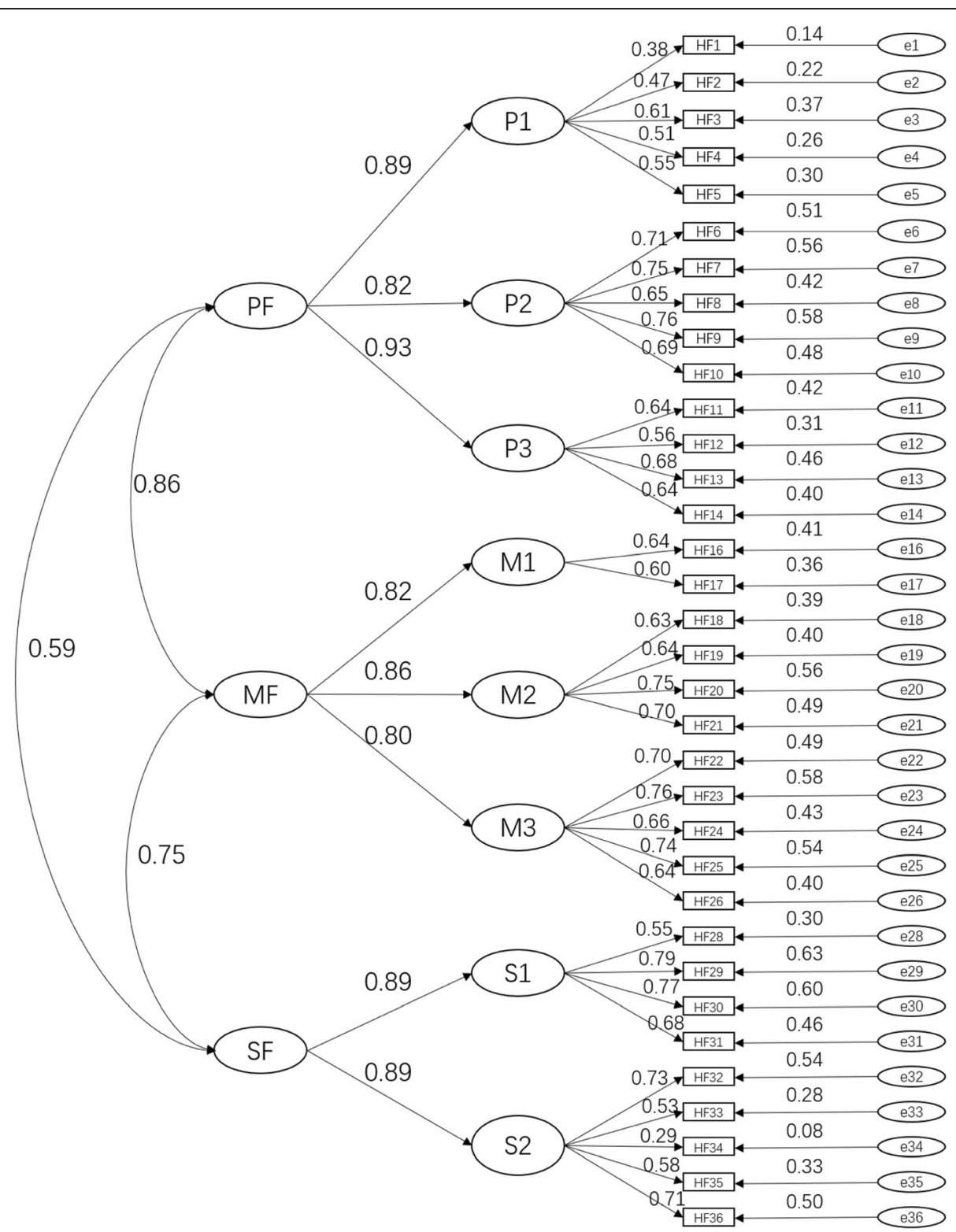

Fig. 2 The revised overall model of HFMS V1.0. Notes: The scale entries (HF1-HF36) were observed variables. P1, P2, P3, M1, M2, M3, S1, S2, PF, MF, SF were potential variables, where P1, P2, P3, M1, M2, M3, S1, S2 were endogenous variables and PF, MF, SF were exogenous variables. PF= Physical Fitness subscale, MF = Mental Fitness subscale, SF=Social Fitness subscale. P1 = Organ function, P2 = Motor function, P3 = Physical adaptive capacity, M1 = Psychological cognition, M2 = Resilience, M3 = Stress response, S1 = Role adaptation, S2 = Social resource and social support 
Table 4 Correlation coefficient matrix between dimensions and subscales

\begin{tabular}{|c|c|c|c|c|c|c|c|c|}
\hline & $\begin{array}{l}\text { Organ } \\
\text { function }\end{array}$ & $\begin{array}{l}\text { Motor } \\
\text { function }\end{array}$ & $\begin{array}{l}\text { Physical } \\
\text { adaptive } \\
\text { capacity }\end{array}$ & $\begin{array}{l}\text { Psychological } \\
\text { cognition }\end{array}$ & Resilience & $\begin{array}{l}\text { Stress } \\
\text { response }\end{array}$ & $\begin{array}{l}\text { Role } \\
\text { adaptation }\end{array}$ & $\begin{array}{l}\text { Social resource and } \\
\text { social support }\end{array}$ \\
\hline Organ function & 1 & & & & & & & \\
\hline Motor function & $.485^{* *}$ & 1 & & & & & & \\
\hline $\begin{array}{l}\text { Physical adaptive } \\
\text { capacity }\end{array}$ & $.480^{* *}$ & $.611^{* *}$ & 1 & & & & & \\
\hline $\begin{array}{l}\text { Psychological } \\
\text { cognition }\end{array}$ & $.388^{* *}$ & $.404^{* *}$ & $.374^{* *}$ & 1 & & & & \\
\hline Resilience & $.432^{* *}$ & $.438^{* *}$ & $.513^{* *}$ & $.442^{* *}$ & 1 & & & \\
\hline Stress response & $.490^{* *}$ & $.340^{* *}$ & $.480^{* *}$ & $.343^{* *}$ & $.572^{* *}$ & 1 & & \\
\hline Role adaptation & $.410^{* *}$ & $.372^{* *}$ & $.358^{* *}$ & $.358^{* *}$ & $.444^{* *}$ & $.501^{* *}$ & 1 & \\
\hline $\begin{array}{l}\text { Social resource and } \\
\text { social support }\end{array}$ & $.248^{* *}$ & $.226^{* *}$ & $.170^{* *}$ & $.296^{* *}$ & $.338^{* *}$ & $.278^{* *}$ & $.527^{* *}$ & 1 \\
\hline $\begin{array}{l}\text { Physical fitness } \\
\text { subscale }\end{array}$ & $.759^{* *}$ & $.882^{* *}$ & $.809 * *$ & $.467^{* *}$ & $.551^{* *}$ & $.511^{* *}$ & $.442^{* *}$ & $.257^{* *}$ \\
\hline $\begin{array}{l}\text { Mental fitness } \\
\text { subscale }\end{array}$ & $.550^{* *}$ & $.471^{* *}$ & $.573^{* *}$ & $.597^{* *}$ & $.840^{* *}$ & $.886^{* *}$ & $.552^{* *}$ & $.366^{* *}$ \\
\hline Social fitness subscale & $.353^{* *}$ & $.315^{* *}$ & $.278^{* *}$ & $.357^{* *}$ & $.438^{* *}$ & $.431^{* *}$ & $.846^{* *}$ & $.886^{* *}$ \\
\hline
\end{tabular}

** significant, $p<0.001$. The bold correlation coefficient is the correlation coefficient between each dimension and the corresponding subscale

good convergent validity. Additionally, the correlation coefficients among the dimensions were lower than the correlation coefficients between the dimensions and the corresponding subscale score, which indicated that the scale had good discriminant validity (Table 4).

\section{Reliability}

The Cronbach's alpha of HFMS V1.0 scale was 0.920, and the Guttman coefficients of the HFMS V1.0 total scale was 0.946 . Three subscales reliability results, means and standard deviations are provided in Table 5. The highest and lowest scores accounted for very low proportions in the HFMS V1.0 total scale and the three subscales of PF, MF, and SF, without ceiling and floor effect.

All HFMS items exhibited satisfactory correlation with the corresponding subscale scores (Spearman's $r>0.30$ ) and ranged from 0.421 to 0.724 . The Cronbach's $\alpha$ values were above the threshold of 0.70 and ranged from 0.803 to 0.869 (Table 6).

Table 7 shows the test-retest reliability statistics in older adults from Guangzhou for the HFMS V1.0 and three subscale: PF, MF, and SF. The ICC values ranged from 0.752 (SF) to 0.837 (MF), and the ICC of HFMS V1.0 was 0.878 .

\section{Discussion}

The increase in life expectancy and the decline in fertility are facilitating the aging of the world's population [1]. In order to promote healthy aging, the WHO has released the World report on ageing and health, emphasizing that fitness is related to health, which hinges on the intrinsic capacity of the individual and environmental characteristics [59]. However, the current assessment of fitness is mostly limited to a certain dimension of physiology, psychology and society, and there is a lack of comprehensive healthy fitness measurement approaches. In this study, we aimed to assess the reliability and validity of the HFMS V1.0 for measuring the healthy fitness of the elderly.

Our results demonstrated that HFMS V1.0 scale exhibits acceptable internal consistency (Cronbach's alpha coefficient $=0.920$, split-half coefficient $=0.946>0.70)$, which is consistent with data of previous findings (Cronbach's alpha coefficient $=0.920$, split-half coefficient $=$ 0.763) [48]. This indicates that all items in the HFMS

Table 5 Internal consistency reliability results, means and standard deviation, floor and ceiling effects of the HFMS V1.0 (N=777)

\begin{tabular}{lllllll}
\hline Scale & Cronbach's alpha & Guttman coefficient & Mean & SD & Floor (\%) & Ceiling (\%) \\
\hline HFMS V1.0 & 0.920 & 0.946 & 57.37 & 11.00 & $15.44(0.13 \%)$ & $91.91(0.13 \%)$ \\
PF & 0.869 & 0.884 & 53.37 & 13.37 & $12.50(0.13 \%)$ & $92.86(0.13 \%)$ \\
MF & 0.865 & 0.893 & 61.07 & 13.04 & $13.64(0.13 \%)$ & $100.00(0.13 \%)$ \\
SF & 0.853 & 0.905 & 59.09 & 13.48 & $19.44(0.26 \%)$ & $94.44(0.37 \%)$ \\
\hline
\end{tabular}

PF physical fitness subscale, MF mental fitness subscale, SF social fitness subscale. SD standard deviation 
Table 6 Item-Total Correlation and Cronbach's Alpha of three subscale $(N=777)$

\begin{tabular}{|c|c|c|}
\hline Item & Item-Total Correlation & Cronbach's Alpha if Item Deleted \\
\hline \multicolumn{3}{|c|}{ Physical Fitness subscale } \\
\hline HF1 & $.425^{* *}$ & 0.869 \\
\hline HF2 & $.476^{* *}$ & 0.866 \\
\hline HF3 & $.565^{* *}$ & 0.861 \\
\hline HF4 & $.478^{* *}$ & 0.866 \\
\hline HF5 & $.530^{* *}$ & 0.865 \\
\hline HF6 & $.647^{* *}$ & 0.854 \\
\hline HF7 & $.705^{* *}$ & 0.853 \\
\hline HF8 & $.646^{* *}$ & 0.857 \\
\hline HF9 & $.724^{* *}$ & 0.851 \\
\hline HF10 & $.663^{* *}$ & 0.856 \\
\hline HF11 & $.629^{* *}$ & 0.858 \\
\hline HF12 & $.537^{* *}$ & 0.862 \\
\hline HF13 & $.612^{* *}$ & 0.859 \\
\hline HF14 & $.613^{* *}$ & 0.859 \\
\hline \multicolumn{3}{|c|}{ Mental Fitness subscale } \\
\hline HF16 & $.516^{* *}$ & 0.865 \\
\hline HF17 & $.486^{* *}$ & 0.865 \\
\hline HF18 & $.580^{* *}$ & 0.856 \\
\hline HF19 & $.618^{* *}$ & 0.854 \\
\hline HF20 & $.689^{* *}$ & 0.850 \\
\hline HF21 & $.703^{* *}$ & 0.848 \\
\hline HF22 & $.720^{* *}$ & 0.848 \\
\hline HF23 & $.703^{* *}$ & 0.850 \\
\hline HF24 & $.653^{* *}$ & 0.853 \\
\hline HF25 & $.724^{* *}$ & 0.847 \\
\hline HF26 & $.628^{* *}$ & 0.855 \\
\hline \multicolumn{3}{|c|}{ Social Fitness subscale } \\
\hline HF28 & $.635^{* *}$ & 0.819 \\
\hline HF29 & $.687^{* *}$ & 0.807 \\
\hline HF30 & $.687^{* *}$ & 0.808 \\
\hline HF31 & $.682^{* *}$ & 0.808 \\
\hline HF32 & $.705^{* *}$ & 0.806 \\
\hline HF33 & $.641^{* *}$ & 0.816 \\
\hline HF34 & $.421^{* *}$ & 0.840 \\
\hline HF35 & $.655^{* *}$ & 0.811 \\
\hline HF36 & $.720^{* *}$ & 0.803 \\
\hline
\end{tabular}

V1.0 scale have good correlation with similar feature. The test-retest reliability of HFMS V1.0 scale was evaluated through examination of ICC value, as the result of ICC $=0.878$ confirms the scale stability over time. In the study, the highest and lowest scores accounted for very low proportions in the HFMS V1.0 total scale and the three subscales of PF, MF, and SF. No ceiling effect or floor effect was observed in the HFMS V1.0, indicating that these aggregate scores sensitively reflect the changes in the healthy fitness of the Chinese elderly.

The test on convergent validity of the HFMS V1.0 scale indicates the strong correlation $(r=0.597-0.886)$ between each dimension and subscales. In the test on discriminant validity, the correlation coefficient between each dimension value and the total value was higher than that between each dimension, which indicates great convergent and discriminant validity of the HFMS V1.0 scale.

Besides, the results from EFA and CFA further depict the factorial validity of the HFMS V1.0 scale. In the EFA, the extracted 10 factors are responsible $65.71 \%$ of the variability. Among the 10 factors, factor 1 (motor function) accounts for $28.56 \%$ of the variability, suggesting that individual's motor function should deserve more attention. Different from our conclusion, a previous study by Lijie Jiang [48] points out stress response as the main impact factor responsible for $9.485 \%$ of the variability. Such difference may be due to the compositions of the subjects; the subjects of our study were retired elderly while Li's research focused on civil servants, most of whom were under 30 years old (47.5\%). Physical fitness is related to age. The decline in function activity of skeletal muscle [60] affects the balance and walking ability of the elderly [61]. It is noted that physical fitness reaches a peak at the age of 20 [62]. Civil servants are more available to mental disorders. According to relevant data, $33.8 \%$ of civil servants suffers from high work pressure [63], while some $47 \%$ of compensatory mental disorders are triggered by work pressure [64]. Individuals under long-term stress are prone to psychological discomfort and negative emotional reactions [65]. The stress response is significantly related to psychological health [66].

In the CFA, we set up a second-order factor model to examine the scale fitness based on theoretical structure of the HFMS V1.0 scale. The standardized path coefficients between the dimensions and the subscales ranged from 0.78 to 0.95 indicating HFMS V1.0 has great path association. The initial model failed to indicate acceptable fitness. But after adjustment of fixed parameters and establishment of covariation relationship between the error terms based on the MI value and the estimated parameter change, the overall model of the scale indicated good fitness $(\mathrm{CMIN} / \mathrm{DF}=2.796$, $\mathrm{RMSEA}=0.048$, $\mathrm{IFI}=0.914, \mathrm{TLI}=0.902, \mathrm{CFI}=0.913)$.

The main advantage of HFMS V1.0 scale is comprehensive evaluation of healthy fitness with systematic structure as the scale involves examinations of physical, mental fitness, and social fitness. Our study first confirms the reliability and validity of HFMS V1.0 in the Chinese elderly population through EFA and 
Table 7 Test-retest (24 h to 1 week apart) reliability of the HFMS V1.0 among older adults in Guangzhou $(n=75)$

\begin{tabular}{llllll}
\hline Scale & Test mean (SD) & Re-test mean (SD) & ICC & $\mathbf{9 5 \% ~ C l}$ & $\mathbf{a}$ \\
\hline HFMS V1.0 & $60.79(9.10)$ & $59.59(8.73)$ & 0.878 & $0.807-0.923$ \\
PF & $57.48(10.14)$ & $56.20(10.22)$ & 0.797 & $0.679-0.871$ & 0.781 \\
MF & $63.88(10.83)$ & $61.22(13.11)$ & 0.837 & $0.735-0.899$ \\
SF & $62.16(12.51)$ & $62.89(8.73)$ & 0.752 & $0.608-0.844$ \\
\hline
\end{tabular}

PF physical fitness subscale, MF mental fitness subscale, $S F$ social fitness subscale, $S D$ standard deviation, ICC intraclass correlation coefficient, $C I$ confidence interval, a Cronbach's alpha

CFA, when describing the operational definition of healthy fitness.

\section{Limitations}

Firstly, all the data in this study were collected from questionnaires filled out by the subjects of the elderly with diminished cognitive abilities, so there might exist certain potential reporting biases. Secondly, the selfreport method was adopted through which the participants made an evaluation of their health fitness in the past month, but there may be a recall bias. Besides, we used a multi-stage stratified sampling method and sampling errors are still inevitable. Though the present study provides evidence for effective application of HFMS V1.0, the survey sampling was limited to four regions of the city of Guangzhou. Large-scale investigations and empirical studies should be further conducted in China in the future.

\section{Generalisability}

As far as we know, this study first uses HFMS V1.0 to assess the health fitness level of the elderly, but the participants in all stages of this study were selected from Guangzhou city. Therefore, what extent the study sample reflects the health condition of entire Chinese elderly population remains unknown. The HFMS V1.0 should be tested among the elderly from different regions of China, thereby contributing to nationwide application of the scale. Additionally, considering cultural differences between different countries, the use of this scale in other countries requires a further cross-cultural revision and verification.

\section{Conclusion}

This study confirms that the HFMS V1.0 scale has acceptable reliability and validity in the assessment of the healthy fitness of the elderly in Guangzhou, and it can be used as an effective and reliable quantitative measurement of the healthy fitness level of the elderly in other regions of China. These evidences might lay a good foundation for further research on the healthy fitness norms of the elderly and their related factors.
Acknowledgements

We thank all study participants and investigators for their assistance in this research.

\section{Authors' contributions \\ $\mathrm{QL}$ and $\mathrm{HZ}$ conducted the analyses, interpreted the results, and participated in developing the first draft. $H Q, C H, L J, G J, W W, Z H$ and JX analyzed the data and drafted the manuscript. All authors read and approved the final version to be submitted.}

\section{Funding}

This research was supported by the National Natural Science Fund, National Natural Science Foundation of China (No: 71673126), the Science and Technology Planning Project of Guangzhou City of China (No: 201803010089), and a grant from the Public Health Service System Construction Research Foundation of Guangzhou (2018-2020). The funders had no role in study design, data collection and analysis, decision to publish, or preparation of the manuscript.

\section{Availability of data and materials}

Data are available upon reasonable request. Readers can contact Xu Jun (drugstat@163.com) to submit raw data access requirements.

\section{Declarations}

Ethics approval and consent to participate

This study was approved by the Ethics Committee of Nanfang Hospital of Southern Medical University (No. NFEC-2020-288). All protocols are carried out in accordance with relevant guidelines and regulations. At the beginning of this study, participants were informed about the purpose of this study and their right to voluntarily participate. Written informed consent was obtained from all participants for the study.

\section{Consent for publication}

Not applicable.

\section{Competing interests}

The authors declare that they have no competing interests.

\section{Author details}

'Department of Sanitation Economy Administration, Nanfang Hospital, Southern Medical University, Guangzhou, Guangdong Province, China.

${ }^{2}$ School of Health Management, Southern Medical University, Guangzhou, Guangdong Province, China. ${ }^{3}$ Guangzhou Cadre Health Management Center, Guangzhou, Guangdong Province, China. ${ }^{4}$ Guangdong Provincial Occupational Disease Prevention and Control Hospital, Guangzhou, Guangdong Province, China.

Received: 19 January 2021 Accepted: 5 May 2021

Published online: 30 May 2021

\section{References}

1. Beard JR, Officer AM, Cassels AK. The world report on ageing and health. Gerontologist. 2016;56(Suppl 2):S163-6. https://doi.org/10.1093/geront/ gnw037.

2. National Bureau of Statistics. The growth rate of the total population slows down, and the level of urbanization continues to rise. 2020. http://www.sta ts.gov.cn/tjsj/zxfb/202001/t20200119_1723767.html. 
3. Yifan Y, Xueyong Z, Jie C, Lei Q. Report on Healthy Aging Index of China's Large and Medium Cities (2019 2020) [M]. Beijing: Social Sciences Literature Press; 2020.

4. Staudinger UM, Finkelstein R, Calvo E, Sivaramakrishnan K. A Global View on the Effects of Work on Health in Later Life. Gerontol. 2016; 56(Suppl_2):S281-92.

5. Lina Z, Xiaoxuan Z, Lulu S, Hui L, Bingqing L, Mingyang W, et al. Relationship between weight change and the changes in blood pressure, blood glucose and blood lipid profiles in middle-aged and elderly Chinese people: a cohort study. Chinese J Prev Med. 2018;52(09):915-21.

6. Changhu L, Song H, Yongjun M, Ang X. Research Progress of frailty. Chinese Gen Pract. 2017;20(16):2025-33. https://doi.org/10.3969/j.jssn.1007-9572.2017.16.024.

7. Chang X, Chenglin Z, Yang M. Research of lifestyle on the delay of cognitive function decline of elderly people. China Sports Sci. 2014;34(05):35-44.

8. Yiling W, Lin W, Shanshang Z. Using the Chinese version of the elderly depression scale to analyze the current status of depression in the elderly in Jinhua City. Chin J Gerontol. 2018;38(02):453-5. https://doi.org/10.3969/j. issn.1005-9202.2018.02.084.

9. LaMei G, JiaZhi S. Preliminary study on application value of health-related physical fitness assessment in aging society. E-J Transl Med. 2017;4(03):56-8.

10. Kühn S, Rieger UM. Health is a state of complete physical, mental and social well-being and not merely absence of disease or infirmity. Surg Obes Relat Dis. 2017;13(5):887. https://doi.org/10.1016/.joard.2017.01.046.

11. Hong R, Wenhua X. A Theoretical Study on Structure-dimensional of Human Physical Adaptation. J Beijing Sport Univ. 2007;30(11):1505-1507+1514.

12. Sturmberg JP. Health: a personal complex-adaptive state. Handbook of systems and complexity in health. New York: Springer; 2013:231-42. https:// link.springer.com/chapter/10.1007/978-1-4614-4998-0_15.

13. Ortega FB, Cadenas-Sanchez C, Lee D, Ruiz JR, Blair SN, Sui X. Fitness and fatness as health markers through the lifespan: an overview of current knowledge. Prog Prev Med. 2018;3(2):e13.

14. Du C, Li B, Cheng Y, Li C, Liu H, Yao R. Influence of human thermal adaptation and its development on human thermal responses to warm environments. Build Environ. 2018;139:134-45. https://doi.org/10.1016/j. buildenv.2018.05.025.

15. Li M, Tiefeng F, Ji Q, Xiaohong G, Wenli Z, Xiang L, et al. Study on crosscultural adaptation and health status in medical international students. Chinese J Med Educ Res. 2011;10(11):1379-82. https://doi.org/10.3760/cma.j. issn.2095-1485.2011.11.034.

16. Lee MS, Tanaka K. Significance of health fitness appraisal in an aging society. Appl Hum Sci. 1997;16(4):123-31. https://doi.org/10.2114/jpa.16.123.

17. Perez-Sousa MA, Olivares PR, Escobar-Alvarez JA, Parraça JA, Gusi N. Fitness as mediator between weight status and dimensions of health-related quality of life. Health Qual Life Outcomes. 2018;16(1):155. https://doi.org/1 0.1186/s12955-018-0981-0.

18. Ho TW, Tsai HH, Lai JF, Chu SM, Liao WC, Chiu HM. Physical fitness cognition, assessment, and promotion: a cross-sectional study in Taiwan. Plos One. 2020;15(10):e240137.

19. De Sousa RA, Improta-Caria AC, Aras-Júnior R, de Oliveira EM, Soci ÚPR, Cassilhas RC. Physical exercise effects on the brain during COVID-19 pandemic: links between mental and cardiovascular health. Neurol Sci. 2021;42(4):1325-34.

20. Chonggao X, Ning Z, Qing M, Shan L. From fitness to wellness--a historical review of the development of the American physical fitness education program. J Xi'an Institute Transl. 2016;23:16-20.

21. Clayre P. Physical Best-PR Tool for the Elementary Physical Educator. J Phys Educ Recreation Dance Resto. 1990;7(62):23-6.

22. Wei Z. Juvenile physical fitness assessment system in united state and Japan. Hubei Sports Sci. 2017;36(8):671-4.

23. Zhili Y. Ishii Masaru. Comparative study on the standards for constitutional health of Chinese and Japanese students. J Phys Educ. 2005;12(6):105-8.

24. National Department of Sport. National Fitness Standards Manual. Beijing: People's Sports Publishing House; 2003.

25. Chongmin J, Daozhong Y, Chengye J, Rui C. The formulation of "National Fitness Standards.". Sports Sci. 2004;24(3):33-6. https://doi.org/10.16469/j. css.2004.03.011.

26. Prince M, Patel V, Saxena S, Maj M, Maselko J, Phillips MR, et al. No health without mental health. Lancet. 2007;370(9590):859-77. https://doi.org/10.101 6/S0140-6736(07)61238-0.

27. Rhodes, Anne E. Mental Health: Facing the Challenges, Building Solutions: Report from the WHO European Ministerial Conference[J]. Can J Public
Health. 2008;99(2):156-7. https://schlr.cnki.net/en/Detail/index/SPQDLAST/ SPQD00000232072.

28. Jia W, Tingting $X$. On the cultivation of the psychological adaptability of "cognition + emotion + motivation" in the mixed teaching mode. Comp Stud Cult Innov. 2020;0(5):36-8.

29. Stanley SH, Ng SM, Laugharne J. The 'Fit for Life' exercise programme: improving the physical health of people with a mental illness. Psychol Health Med. 2019;24(2):187-92. https://doi.org/10.1080/13548506.2018.15303 66

30. Robinson POLG. Conceptualising and measuring mental fitness: a Delphi study. Int J Wellbeing. 2015;1(5):53-73.

31. Bolier L, Haverman M, Kramer J, Westerhof GJ, Riper H, Walburg JA, et al. An internet-based intervention to promote mental fitness for mildly depressed adults: randomized controlled trial. J Med Internet Res. 2013;15(9):e200. https://doi.org/10.2196/jmir.2603.

32. Huichang C, Zengshou D, Jianji C. Development of adolescent psychological adaptability scale (APAS) and its preliminary norm. Psychol Dev Educ. 1995;3:28-32.

33. Yu Y, Wan C, Huebner ES, Zhao X, Zeng W, Shang L. Psychometric properties of the symptom check list 90 (SCL-90) for Chinese undergraduate students. J Ment Health. 2019;28(2):213-9. https://doi.org/10.1080/0963823 7.2018.1521939

34. Yue T, Li Q, Wang R, Liu Z, Guo M, Bai F, et al. Comparison of hospital anxiety and depression scale (HADS) and Zung self-rating anxiety/ depression scale (SAS/SDS) in evaluating anxiety and depression in patients with psoriatic arthritis. Dermatology. 2020;236(2):170-8. https://doi.org/10.11 59/000498848.

35. Cavell TA. Social adjustment, social performance, and social skills: a tricomponnent model of social competence. J Clin Child Psychol. 1990;2(19): $111-22$.

36. Yunshan G, Lina Z, Xiaoling M, Hanbing W, Xueyan B. A summary of research on college Students' social adaptability. Sch Party Building Ideol Educ. 2015;0(9):79-81.

37. Yangu P, Dajun Z, Guangzeng L, Wanfen C. The influencing factors of college Students' social adaptation and the ways of training-research from psychology. J Southwest Univ. 2016;42(5):108-113,191.

38. Tracey TJ, Sherry P, Keitel M. Distress and help-seeking as a function of person-environment fit and self-efficacy: a causal model. Am J Community Psychol. 1986;14(6):657-76. https://doi.org/10.1007/BF00931341.

39. Constantino JN, Hashemi N, Solis E, Alon T, Haley S, McClure S, et al. Supplementation of urban home visitation with a series of group meetings for parents and infants: results of a "real-world" randomized, controlled trial. Child Abuse Negl. 2001;25(12):1571-81. https://doi.org/10.1016/S0145-2134 (01)00292-7.

40. Donkers HW, Van der Veen DJ, Teerenstra S, Vernooij-Dassen MJ, NijhuisVander SM, Graff M. Evaluating the social fitness Programme for older people with cognitive problems and their caregivers: lessons learned from a failed trial. BMC Geriatr. 2018;18(1):237. https://doi.org/10.1186/s12877-0180927-8.

41. La Malfa G, Lassi S, Bertelli M, Albertini G, Dosen A. Emotional development and adaptive abilities in adults with intellectual disability. A correlation study between the scheme of appraisal of emotional development (SAED) and Vineland adaptive behavior scale (VABS). Res Dev Disabil. 2009;30(6): 1406-12. https://doi.org/10.1016/j.ridd.2009.06.008.

42. Tse WS, Bond AJ. Psychometric analysis of the Chinese version of social adaptation self-evaluation scale (C-SASS). Psychiatry Res. 2007;153(3):277-81. https://doi.org/10.1016/j.psychres.2006.09.009.

43. Bhattacharya S. Adaptive behavior scale-refinement. Ment Retard. 1973;11(1): 27.

44. Li L, Peng T, Liu R, Jiang R, Liang D, Li X, et al. Development of the psychosomatic symptom scale (PSSS) and assessment of its reliability and validity in general hospital patients in China. Gen Hosp Psychiatry. 2020;64: 1-8. https://doi.org/10.1016/j.genhosppsych.2020.01.008.

45. Callahan D. The WHO definition of 'health'. Hastings Center Stud. 1973;1(3): 77-87. https://doi.org/10.2307/3527467.

46. Yan W. Comprehensive Evaluation on the Health Quality of Physical, Mental and Social Adaptation of College Students in ShiHeZi University[D]. Xinjiang: ShiHeZi University; 2007. https://kns.cnki.net/kcms/detail/detail.a spx?dbcode=CMFD\&dbname $=$ CMFD2007\&filename $=2007190968$.nh\&v $=$ 3GwyNImT1RXh46xpErlpbOJEAWW1IMPfmwSFYn22ggOd683 IUMpHUUUOr7j5cHwK. 
47. Lijie J, Jun $X$, Chen H, Yefang F, Mengyao X, Chengkai W, et al. The Construction of an Index System for Health-related Fitness Evaluation. Chinese Gen Pract. 2020;23(26):3348-54. https://doi.org/10.12114/j.issn.10079572.2020.00.392.48.

48. Lijie J. Development of Healthy Fitness Measurement Scale[D]. Guangdong: Southern Medical University; 2020.https://doi.org/10.27003/d.cnki.gojyu.2020, $000701 \mathrm{https}: / \mathrm{kns} . \mathrm{cnki.net} / \mathrm{kcms} / \mathrm{detail} /$ detail.aspx? dbcode=CMFD\&dbname= CMFD202101\&filename $=1020116307 . n h \& V=a z X V S R c D u m H Q c 2 Z V g D k J J S A$ 8oekl24hLzLNwTKFfskOisjf1dPmc2XORJj2\%25mmd2FPqD9.

49. Xu Y. Social survey design and data analysis - from topic to publication. Chongqing: Chongqing University Press; 2011.

50. Hongyun L. Advanced statistics for psychological. Beijing: Renmin University Press; 2019.

51. Bowling A. Measuring health: a review of quality of life measurement scales. Milton Keynes: open university press; 1991.

52. Xiao H, Chao Y, Ailing L, Hong J. Construction of the patient safety culture evaluation scale for the three-level general hospital. Chinese J Hosp Adm. 2014;41(19):3545-7.

53. Koo TK, Li MY. A guideline of selecting and reporting Intraclass correlation coefficients for reliability research. J Chiropr Med. 2016;15(2):155-63. https:// doi.org/10.1016/j.jcm.2016.02.012.

54. Montazeri A, Vahdaninia M, Mousavi SJ, Omidvari S. The Iranian version of 12-item short form health survey (SF-12): factor structure, internal consistency and construct validity. BMC Public Health. 2009;9(1):341. https:// doi.org/10.1186/1471-2458-9-341.

55. Su SW, Wang D. The reliability and validity of short Form- 12 health survey version 2 for Chinese older adults. Iran J Public Health. 2019;48(6):1014-24.

56. Stacciarini TS, Pace AE. Confirmatory factor analysis of the appraisal of selfcare agency scale - revised. Rev Lat Am Enfermagem. 2017;25:e2856.

57. Wellman RJ, DiFranza JR, O'Loughlin J. Confirmatory factor analysis of the autonomy over tobacco scale (AUTOS) in adults. Addict Behav. 2015;50:21721. https://doi.org/10.1016/j.addbeh.2015.06.033.

58. Bosten JM, Goodbourn PT, Bargary G, Verhallen RJ, Lawrance-Owen AJ, Hogg RE, et al. An exploratory factor analysis of visual performance in a large population. Vis Res. 2017;141:303-16. https://doi.org/10.1016/j.visres.2 017.02.005.

59. Beard JR, Officer A, de Carvalho IA, Sadana R, Pot AM, Michel JP, et al. The world report on ageing and health: a policy framework for healthy ageing. Lancet. 2016;387(10033):2145-54. https://doi.org/10.1016/50140-6736(1 5)00516-4.

60. Pansarasa O, Castagna L, Colombi B, Vecchiet J, Felzani G, Marzatico F. Age and sex differences in human skeletal muscle: role of reactive oxygen species. Free Radic Res. 2000;33(3):287-93. https://doi.org/10.1080/1071 5760000301451.

61. Ito Y, Aoki T, Sato T, Oishi K, Ishii K. Comparison of quadriceps setting strength and knee extension strength tests to evaluate lower limb muscle strength based on health-related physical fitness values in elderly people. BMJ Open Sport Exerc Med. 2020;6(1):e753.

62. Wattanathorn J, Muchimapura S, Tong-Un T, Saenghong N, Thukhum-Mee W. Sripanidkulchai B. Positive modulation effect of 8-week consumption of Kaempferia parviflora on health-related physical fitness and oxidative status in healthy elderly volunteers. Evid Based Complement Alternat Med. 2012; 2012:732816.

63. Guan $S$, Xiaerfuding X, Ning L, Lian Y, Jiang Y, Liu J, Ng TB. Effect of Job Strain on Job Burnout, Mental Fatigue and Chronic Diseases among Civil Servants in the Xinjiang Uygur Autonomous Region of China. Int J Environ Res Public Health. 2017;14(8):872

64. Yamauchi T, Yoshikawa T, Sasaki T, Matsumoto S, Takahashi M, Suka M, et al. Cerebrovascular/cardiovascular diseases and mental disorders due to overwork and work-related stress among local public employees in Japan. Ind Health. 2018;56(1):85-91. https://doi.org/10.2486/indhealth.2017-0131.

65. Zhang L, Fu J, Yao B, Zhang Y. Correlations among work stressors, work stress responses, and subjective well-being of civil servants: empirical evidence from China. Iran J Public Health. 2019;48(6):1059-67.

66. Appelbaum NP, Lee N, Amendola M, Dodson K, Kaplan B. Surgical resident burnout and job satisfaction: the role of workplace climate and perceived support. J Surg Res. 2019;234:20-5. https://doi.org/10.1016/j.jss.2018.08.035.

\section{Publisher's Note}

Springer Nature remains neutral with regard to jurisdictional claims in published maps and institutional affiliations.

\section{Ready to submit your research? Choose BMC and benefit from}

- fast, convenient online submission

- thorough peer review by experienced researchers in your field

- rapid publication on acceptance

- support for research data, including large and complex data types

- gold Open Access which fosters wider collaboration and increased citations

- maximum visibility for your research: over $100 \mathrm{M}$ website views per year

At BMC, research is always in progress.

Learn more biomedcentral.com/submissions 